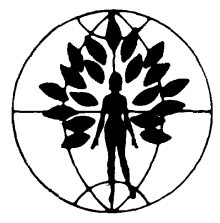

\title{
Contemporary issues in women's health
}

\author{
S. Arulkumaran ${ }^{\mathrm{a}, *}$, T.R.B. Johnson ${ }^{\mathrm{b}}$ \\ ${ }^{a}$ Head of the Department of Obstetrics and Gynaecology, St. George's Hospital Medical School, London, UK \\ ${ }^{\mathrm{b}}$ Bates Professor of Diseases of Women and Children, Chair, Department of Obstetrics and Gynecology, Research Scientist, \\ Center for Human Growth and Development, Professor, Women's Studies, University of Michigan, Ann Arbor, MI, USA
}

The editors of Contemporary Issues in Women's Health solicit reporters and correspondents from throughout the world to make contributions to this section. Please feel free to e-mail or otherwise contract Dr. Timothy Johnson at trbj@umich.edu or Prof. S. Arulkumaran at s.arulkumaran@sghms. ac.uk if you have reports or stories that you would like to have included. We would be happy to attribute the items to those reporters and correpondents who give permission in their transmittal. Otherwise, we will share those reports that we think are of the greatest interest to our readership without attribution.

More (data), more (implications), more (reactions) from the Women's Health Initiative and other fronts regarding hormone therapy (HT)

As we made final corrections on the following paragraphs, yet another notification was received: 'The National Heart, Lung and Blood Institute will make an announcement regarding the estrogenonly arm of the Women's Health Initiative (WHI) at 9:00 am on March 2, 2004.' For up-to-date information, see www.nhlbi.nih.gov/whi.

We previously reported in this column on the Women's Health Initiative (WHI) an NIHfunded project (Int J Gynecol Obstet 2002;79:1-4) that, in 2002, reported results on the effect of com-

*Corresponding author. Tel.: +44-208-725-5959; fax: +44208-725-5958.

E-mail address: sarulkum@sghms.ac.uk (S. Arulkumaran). bined hormone therapy on cardiovascular disease (www.nhlbi.nih.gov/whi/). Since then, several new reports have appeared. The Women's Health Initiative Memory Study (WHIMS), a subgroup of the WHI, investigated the incidence of probable dementia and mild cognitive impairment in 4532 postmenopausal WHI participants 65 and older who were free of probable dementia at baseline. The results demonstrated that combined hormone therapy increased the risk of stroke, dementia, and global cognitive decline, and did not protect against mild cognitive impairment. (JAMA 2003;289:2651-2662) Alzheimer's disease was the most common classification of dementia in both study groups, and the hormone therapy did not significantly prevent mild cognitive impairment. The continued findings of cerebrovascular risks associated with estrogen plus progestin therapy, coupled with the current findings from WHIMS, strongly advocate against recommending hormone replacement therapy 'for prevention of any outcome, including Alzheimer's disease.'

In another WHI study (Hays et al., 'Effects of estrogen plus progestin on health-related qualify of life,' N Engl J Med 2003:348:1939-1854), which assessed health-related quality of life, estrogen plus progesterone, resulted in no significant effects on 'general health, vitality, mental health, depressive symptoms, or sexual satisfaction... Among women age 50 to 54 years of age with moderate to severe vasomotor symptoms at base line, estrogen and 
progesterone improved vasomotor symptoms and resulted in a small benefit in terms of sleep disturbance but no benefit in terms of other quality-oflife outcomes.'

The Food and Drug Administration is requesting that manufacturers update labeling for hormone therapy products (estrogen and combination estrogen and progestin products) for use by postmenopausal women with data from WHIMS. (www.fda.gov/bbs/topics and www.fda.gov/cder/ infopage/estrogens-progestins/default.htm). The FDA has previously updated labeling to reflect the findings of the Women's Health Initiative with respect to cardiovascular disease, breast disease and cancer. The suggested updated labeling and revised labeling guidance include information about current approved uses of the drugs. 'Estrogen and combined estrogen with progestin products are effective for treating moderate to severe hot flashes and night sweats, moderate to severe vaginal dryness, and prevention of osteoporosis associated with menopause.' The suggested label states that if these products are prescribed solely for vaginal symptoms, health care providers are advised to consider the use of topical vaginal products. 'Manufacturers should include WHIMS data in the existing Black Box that contains WHI data on cardiovascular risks based on the WHI study.'

In a recent issue of Lancet (Chlebowski RT, Col N. 'Commentary: Menopausal hormone therapy after breast cancer,' Lancet 2004;363:410-011 and Holmberg L, Anderson H, 'HABITS (hormone replacement therapy after breast cancer) - is it safe? A randomized comparison: trial stopped', Lancet 2004;363:453-55) the early cessation of a trial of 'HRT after breast cancer' in Europe was announced because of an excess risk of new breast cancer events.

The rapidity with which this type of data is reaching patients worldwide is remarkable. (MacLennan $\mathrm{AH}$, 'The trials and tribulations of longterm postmenopausal hormone therapy.' Obstet Gynecol Survey 59;2004:65-67) The important lesson is that well-designed clinical and randomized clinical trials such as these have the possibility to change practice much more rapidly and be transmitted to patients much more rapidly than ever in the past. Keeping up-to-date is more important than ever and the internet will be a key resource for physicians, public agencies, and patients. Hopefully, this will ultimately improve health and patient care.

\section{References}

Romano CJ. More bad news from the Women's Health Initiative.

www.neurologyreviews.com/jul03

www.alzheimers.org/nianews/consumerQ\&A56.htm www.rphlink.com/premprowhi.html

www.medsafe.govt.nz/hot/media/2003/whims.htm www.fda.gov/bbs/topics/NEWS/2004/NEW01022.html www.fda.gov/oc/facesheets/WHI.html

Hays J, Ockene JK, Brunner RL, et al. Effects of estrogen plus progestin on health-related qualify of life. N Engl J Med 2003:348:1939-1854.

MacLennan AH. The trials and tribulations of long-term postmenopausal hormone therapy. Obstet Gynecol Surv 59;2004:65-67.

Chlebowski RT, Col N. Commentary: Menopausal hormone therapy after breast cancer. Lancet 2004;363:410-11.

Holmberg L, Anderson H. HABITS (hormone replacement therapy after breast cancer - is it safe?), a randomized comparison: trial stopped. Lancet 2004;363:453-55.

http://image.thelancet.com/extras/03let/2260web.pdf http://image.thelancet.com/extras/04cmt/17we.pdf

Hsia J, Criqui MH, Rodabough RJ, et al. Estrogen plus progestin and the risk of peripheral arterial disease. Circulation 2004;109:620-626. (www.circulationaha.org)

Wassertheil-Smoller S, Shumaker S, Ockene J, et al. Depression and cardiovascular sequelae in postmenopausal women. Arch Intern Med 2004;164:289-298. (www. $\underline{\text { archinternmed.com) }}$

\section{New insights into pre-eclampsia/toxemia}

Accumulating reports suggest a new target and direction to explain the etiology of the disease called pre-eclamptic/toxemia, or EPH gestosis, which continues to elude our understanding - as evidenced by the many names for the disease. A recent publication (N Engl J Med 2004;350:67283) provides further evidence of an abnormality present in those patients destined to develop preeclampsia. Following initial data publication in the Journal of Clinical Investigation (J Clin Invest 2003:111,649-58) the authors from Beth Israel Hospital have followed up using samples from the National Institutes of Health already collected as 
part of a randomized clinical trial on the disease. They find increased levels of soluble fms-like tyrosine kinase 1 (sFlt-1) and reduced levels of placental growth factor (PlGF) in women in which pre-elampsia develops.

It appears that study in molecular genetics is giving us new insight into this 'great obstetric syndrome' and that a genetic defect in association with other factors may be etiologic-although we have been wrong in our suppositions about this disease before. Stay tuned for updates.

\section{References}

Levine RJ, Maynard SE, Qian C, et al. Circulating angiogenic factors and the risk of preeclampsia. N Engl J Med 2004:350:672-683.

Maynard SE, Jin J-Y, Merchan J, et al. Excess placental soluble fms-like tyrosine kinas 1 (sFlt1) may contribute to endothelial dysfunction, hypertension, and proteinuria in preeclampsia. J Clin Invest 2003;111:649-658.

Koga K, Osuga Y, Yoshino O, et al. Elevated serum soluble vascular endothelial growth factor receptor 1 (sVEGFR-1) levels in women with preeclampsia. J Clin Endocrinol Metab 2003;88:2348-2351. 